\title{
BMJ Global Health Using strategic information for action: lessons from the HIV/AIDS response in Vietnam
}

\author{
Vo Hai Son, ${ }^{1}$ Abu Abdul-Quader, ${ }^{2}$ Amitabh Bipin Suthar ${ }^{3}$
}

To cite: Son VH,

Abdul-Quader A, Suthar AB. Using strategic information for action: lessons from the HIV/AIDS response in Vietnam. BMJ Glob Health 2018;3:e000793. doi:10.1136/ bmjgh-2018-000793

Handling editor Seye Abimbola

Received 21 February 2018 Revised 7 May 2018 Accepted 13 July 2018

Check for updates

(C) Author(s) (or their employer(s)) 2018. Re-use permitted under CC BY-NC. No commercial re-use. See rights and permissions. Published by BMJ.

${ }^{1}$ Vietnam Administration on HIV/ AIDS Control, Vietnam Ministry of Health, Hanoi, Vietnam ${ }^{2}$ Center for Global Health, Centers for Disease Control and Prevention, Hanoi, Viet Nam ${ }^{3}$ Center for Global Health, Centers for Disease Control and Prevention, Atlanta, Georgia, USA

Correspondence to Dr Amitabh Bipin Suthar; icf4@cdc.gov

\section{BACKGROUND}

The capacity of governments to generate highquality, timely, reliable and disaggregated data, and to use these data for planning, are targets within the Sustainable Development Goals. ${ }^{1}$ Health data are the foundation on which governments plan, budget and act against disease epidemics. For example, all countries agreed to achieve the 90-90-90 targets for HIV/ AIDS, wherein $90 \%$ of people with HIV are diagnosed, $90 \%$ of diagnosed people are on treatment and $90 \%$ of people on treatment are virally suppressed. ${ }^{2}$ Ad hoc surveys and studies are currently capturing this information in many settings. ${ }^{3} \mathrm{WHO}$ recently released guidelines for monitoring HIV service delivery at the individual level. ${ }^{4}$ These guidelines recommend the use of electronic case reporting, patient monitoring and vital statistics systems to generate up-to-date data that can characterise service delivery gaps that require programmatic correction. ${ }^{4}$ The guidelines also recommend use of identifiers to link these different information systems. ${ }^{4}$ Many countries will be embarking on the development of health information systems based on the new WHO guidelines. In Vietnam, the Vietnam Authority on HIV/AIDS Control (VAAC) within the Ministry of Health is responsible for control of HIV/ AIDS. VAAC's Division of Disease Surveillance, Monitoring, Evaluation, and Laboratory is responsible for strategic information. This Division has supported the development of health information systems to advance the HIV/AIDS response. The objective of this article is to share lessons learnt from Vietnam to support national adaptation of the new WHO guidelines.

\section{CASE REPORTING SYSTEMS}

Case reporting systems notify a national entity overseeing disease surveillance when a new case of disease has been diagnosed in the country. WHO defines a case of HIV based on positive

\section{Summary box}

New WHO guidelines recommend monitoring individual-level HIV data using case reporting, patient monitoring and vital statistics systems.

- Electronic software, deduplication and case verification may help improve the quality of case reporting data.

- Incorporating HIV treatment into social health insurance as part of universal health coverage changed data routinely generated in patient monitoring systems.

- Strengthening collection of vital statistics at the lowest level of the health system can help improve the sensitivity of the vital statistics system; although systematic and robust ascertainment of cause-ofdeath is needed.

- Leveraging national unique identification may help improve linkages between information systems in the future.

HIV antibody testing that is confirmed by a second HIV antibody test relying on different antigens or different operating characteristics. ${ }^{5}$ In addition to reporting the numbers of cases of HIV that are reported, case reporting systems also allow countries to understand the modes of transmission (eg, injecting drug use, sex work and men who have sex with men) and populations disproportionally affected at the national and subnational levels. In Vietnam, these data are used for national and local planning for service delivery provision and to measure effectiveness of prevention programmes such as eliminating mother-to-child HIV transmission.

In 1987, Vietnam set up the policies and standard operating procedures for an individual-level HIV case reporting system, including collection and processing of patient specimens. ${ }^{6}$ From 1987 to 2004 the case reporting system was exclusively paper-based and largely bottom-up (ie, local levels reported up to the central government with no report or feedback to the local level). ${ }^{7}$ In 2004 Vietnam 


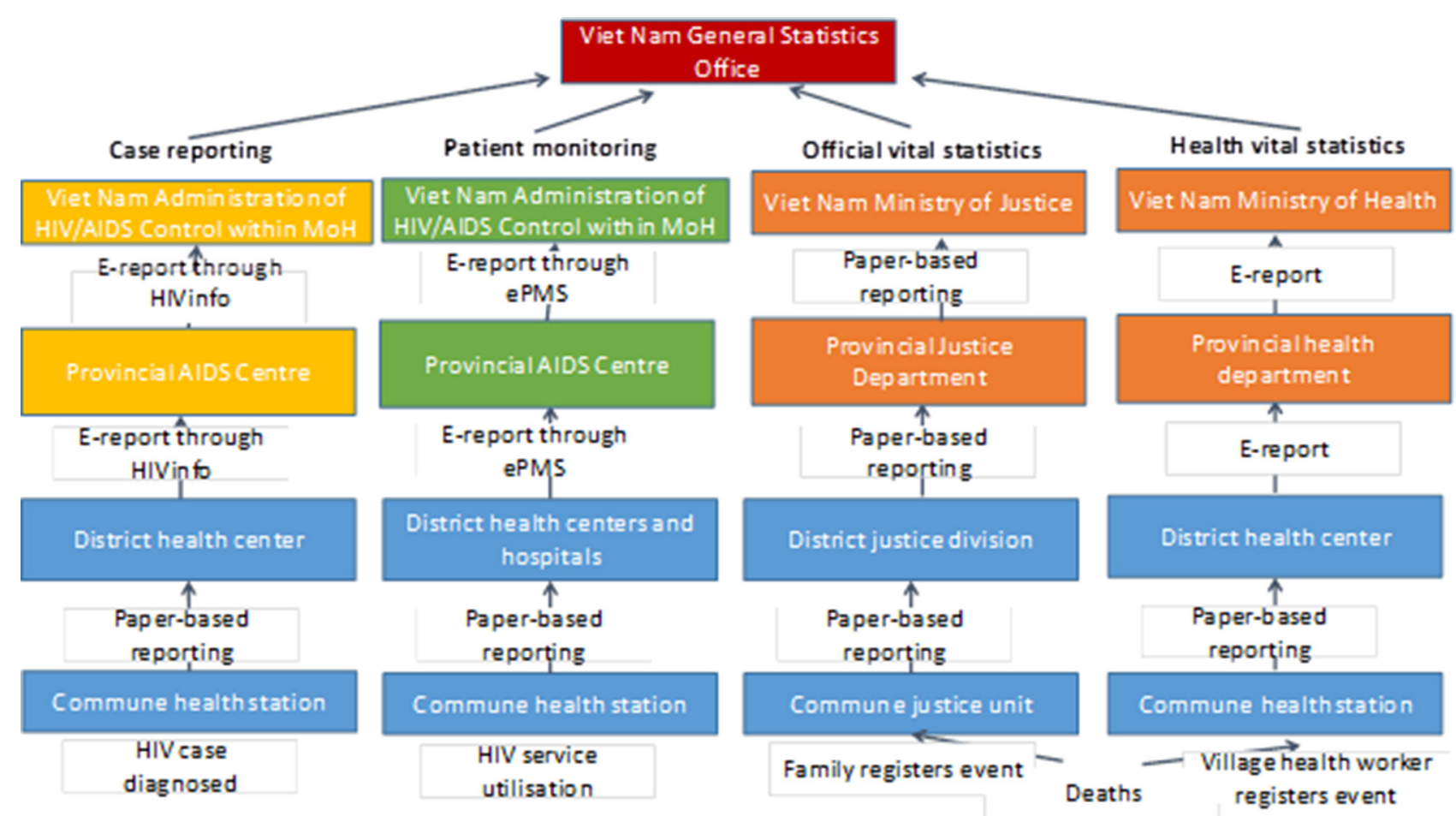

Figure 1 Health system organisation and informatics pathways for case reporting, patient monitoring and vital statistics systems. ePMS, electronic patient monitoring system.

introduced an electronic system to manage cases at the central level, HIVinfo V.1.0 (figure 1). In the first year there were issues with data quality, and refinements to the software were introduced. For example, in 2005 HIVinfo was updated to include deduplication based on name and address. Despite the progress in removing duplicates, there were still dead cases being included in the alive case report data. In 2006, case verification was introduced by having the central government send the list of reported cases to each province, disaggregated by commune, so that commune health staff could update the vital status of HIV cases who have been registered as dead in population registers. ${ }^{8}$ In 2012 , the policy framework was revised to outline recording and reporting requirements to improve implementation of the case reporting system. ${ }^{8}$ A national review in 2015 found that approximately $11 \%$ of cases were dead or duplicate, indicating the need to continue improving the quality of case reporting data. ${ }^{9}$ Currently, HIVinfo is available at all Provincial AIDS Committees and 30\% of districts. ${ }^{10}$ While there are plans to expand HIVinfo in the future, the $30 \%$ of districts currently covered represent higher HIV burden areas while the $70 \%$ not covered have a lower HIV burden and have managed using paper-based registries.

\section{PATIENT MONITORING SYSTEMS}

The HIV community was galvanised into creating patient monitoring systems after the United Nations' ' 3 by 5 ' strategy was announced (ie, treat 3 million people with antiretroviral therapy (ART) by 2005). ${ }^{11}$ In Vietnam, these systems can measure coverage of ART, ascertain outcomes, inform centralised procurement and distribution of medicines and diagnostics, reimburse health insurance, and allow providers to monitor trends in laboratory counts over time. Vietnam started provision of HIV treatment in 2006 and by the end of 2016116000 Vietnamese were on ART, representing $46 \%$ of the 250000 Vietnamese estimated to be living with HIV. ${ }^{10}$

Policies communicating monitoring and evaluation requirements have evolved over time with changing treatment eligibility criteria and viral load introduction for monitoring treatment response. ${ }^{12-14}$ Paper cards and registers remain the foundational sources for patient monitoring in most parts of Vietnam. Selected data from these sources were previously sent upward from health facilities to districts, provinces and then the central government through paper. Given the burden of managing a large treatment cohort over time with paper-based records, Vietnam began transitioning from paper to electronic records in 2013 (figure 1). At this time full electronic medical records, eClinica, were implemented in Ho Chi Minh City to collect all information representing patient-provider interactions. ${ }^{15}$ Early experience with eClinica indicated its utility in settings with high provider informatics literacy, but that alternative means would be needed in settings with low informatics literacy. ${ }^{15}$ For this reason, Vietnam introduced a simple electronic patient monitoring system (ePMS) for reporting individual-level core treatment indicators (ie, enrolment into care, on treatment, retention, lost to follow-up and deaths) in 2014. By the end of 2016, 


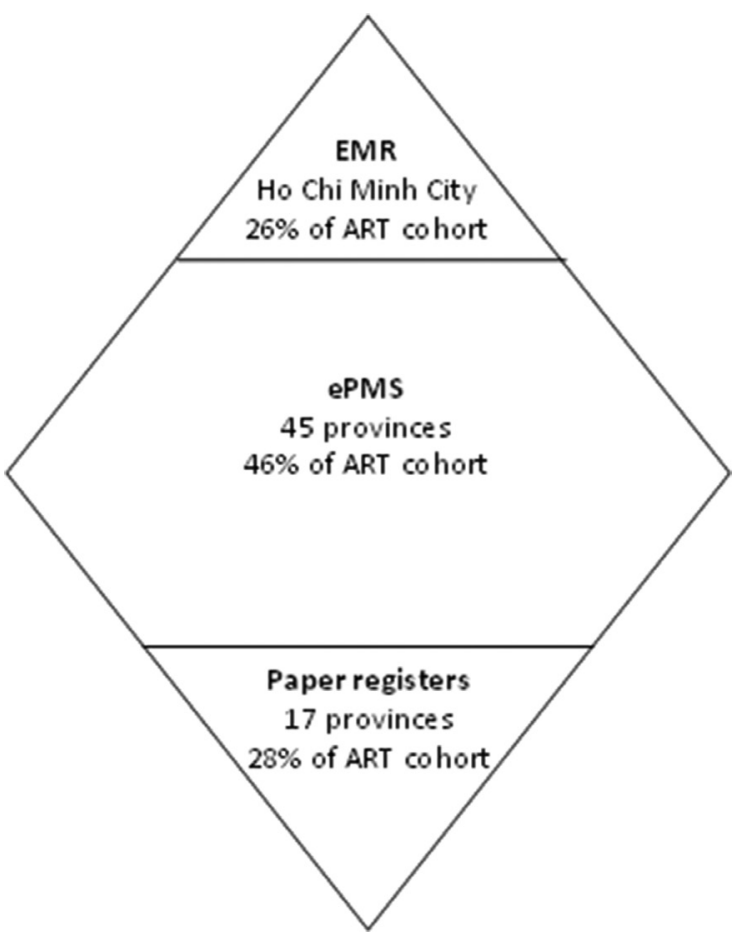

Figure 2 Elements of Vietnam's HIV/AIDS patient monitoring system as of 31 December 2016 (adapted from 2016 National HIV/AIDS Report ${ }^{10}$ ). ART, antiretroviral therapy; ePMS, electronic patient monitoring system; EMR, electronic medical records.

83000 ( $70 \%$ of those on treatment) were being followed through electronic systems; 30000 patients were on eClinica in Ho Chi Minh City while 53000 were on ePMS in 45 provinces (figure 2 ).

As part of reaching universal health coverage, Vietnam recently incorporated HIV treatment into its social health insurance system. ${ }^{16}$ This will require HIV treatment service delivery to transition from preventive medicine centres to hospitals. This complicates the use of ePMS and eClinica because each hospital has their own software, with their own indicators, and different staff that need to be trained on patient monitoring systems. To continue monitoring HIV service delivery over time, an interim solution has been requiring staff to double enter data into the hospital's software and into ePMS/eClinica. Hospitals are starting to use a standard electronic form for all social health insurance reimbursement; using this form for key HIV indicators merits exploration.

\section{VITAL STATISTICS SYSTEMS}

Vital statistics systems allow countries to track births, deaths and causes of deaths to understand demographic shifts and the burden of disease. In Vietnam, death data collected over time also allow disease programmes to track the impact of their response and provide data that may be used to measure cost-effectiveness of programme interventions. Vital statistics and civil registration are coordinated by the Vietnam Ministry of Justice ${ }^{17}$ (figure 1). The cause of death is typically recorded and maintained by the Ministry of Health. ${ }^{18}$ Primary health facilities at the commune-level and district-level hospitals are the service delivery points that have paper registers for recording numbers and causes of deaths as reported by providers. These registers are also designed to record demographics and the family-reported cause of death of deaths occurring outside health facilities through village health workers in rural settings. ${ }^{19}$ Other approaches for recording deaths occurring outside health facilities are needed in urban settings. In 2014 an evaluation indicated there were an estimated 72000 all-cause deaths recorded in commune health registers while overall there were approximately 90000 all-cause deaths reported in all facilities. ${ }^{9}$ This suggests that deaths are not always recorded carefully and checked and that the capacity of commune health staff needs to be strengthened.

\section{IDENTIFICATION FOR HEALTH}

Identification can link and strengthen health data generated by information systems. For example, identification has been used to track people longitudinally within patient monitoring systems, to link case reporting, patient monitoring and vital statistics systems, and for facilitating implementation of universal health coverage. ${ }^{20}$ The Ministry of Public Security, that operates at the national, province and district levels, manages national identification. $^{21}$ To be eligible for a national ID card, citizens must be 16 years old and be listed in a household resident book. This requirement makes it difficult for children, adolescents and homeless people, who may not be registered in resident books, to receive a national ID number. The national ID card uniquely identifies individuals through a national ID number, photo and fingerprint. $^{22}$ Since a new social health insurance card is issued every year, it cannot readily be used for monitoring beneficiaries longitudinally. ${ }^{23}$ Within the HIV programme, eClinica in Ho Chi Minh City maintains a master patient index of patients on treatment including names, national ID numbers and fingerprints. In 2016, 29765 patients on ART were included in this database. With the inclusion of fingerprint biometrics one challenge has been maintaining good performance and speed of the software with the current infrastructure. High-speed telecommunication connectivity and a high-performance servers may help search through fingerprints quickly and increase scale.

\section{CROSS-CUTTING SYSTEM ISSUES}

Data protection is fundamental to ensure people's health data are kept confidential and secure. Key protection elements in Vietnam include: (1) encryption to ensure confidentiality of data (HIVinfo uses encryption which can only be decrypted with separate software), (2) software user limits to secure systems (ePMS and HIVinfo require usernames so that only authorised and essential personnel at each level of the health system can access their data), (3) server hardware that is kept safe and 
hidden to secure systems, and (4) legal frameworks to protect privacy of persons (Vietnam imposes a fine of approximately US\$700-950, or $40 \%-55 \%$ of GNI per capita in 2013, for unauthorised disclosure of HIV/AIDS status)..$^{24} 25$

Stable workforce is key as the health workforce inputs, transmits, analyses and interprets system data. The predominant challenge for the workforce is high turnover since many staff leave for other jobs after completing their training. This problem is the worst at the commune and district levels of government, where most service delivery and data entry occurs. Another challenge is the shortage of staff, as it forces current staff to have multiple responsibilities such as providing for patients and data entry. Since current staff are stretched, data quality can suffer. Moreover, information technology is a relatively new phenomenon with limited experience in rural parts of the country. ${ }^{26}$ Older staff who have not been exposed to computers have difficulty adapting to incorporate it into their normal workflow.

Consistent and stable funding is required for infrastructure and workforce. The available domestic financing for strategic information is largely focused on maintaining systems. External financing, such as the Global Fund and President's Emergency Plan for AIDS Relief (PEPFAR), has been instrumental in expanding the scale and quality of information systems and informatics skill development and maintenance. Unfortunately, this support has been reducing. In terms of workforce financing, central funds are typically used for central and provincial strategic information staff while district and commune staff are usually remunerated through their other responsibilities.

Linkage and communication of different information systems is critical for measuring outcomes over time. Currently there is no software standard across information systems and levels of the health system while government circulars and decrees provide administrative standards. Outcomes have been linked to a core set of approximately 10 indicators encompassing HIV diagnosis, treatment initiation, to death. Case reporting has been linked to ePMS to track the date of enrolment for HIV care, date of treatment initiation and regimen initiated in selected districts. Since there is no unique identifier systematically used in both systems, different algorithms have been developed that are implemented at the provincial and district levels. The first automated algorithm in HIVinfo links people based on full name, address, gender, year of birth and date of HIV confirmation test. A provincial evaluation of this algorithm suggests that it links $60 \%$ of patients. ${ }^{27}$ Manual methods to link information systems using full name, address and year of birth generally have higher performance but consume more time.

\section{LESSONS LEARNT}

Vietnam embarked on developing health information systems based on programme need. Several key lessons may help Vietnam and other countries refine
Box 1 Lessons learnt to improve health information systems

- Leveraging national unique identification could facilitate longitudinal follow-up of social health insurance patients and reduce duplicates within, and across, health information systems.

- Improving overall standards for health information systems can allow health data to easily be shared across the health system. This includes software standards such as Health Level-7, administrative standards to ensure systematic data entry, collection and management, and a core set of monitoring and surveillance indicators across all health facilities to introduce efficiencies in training, oversight and overall coordination.

- Transitioning to fully electronic health records, that is, point-of-care entry by providers without parallel paper-based systems, will help eliminate transcription errors. In the long term this transition could save resources through increased use of data and less time requirements for data collection and transmission.

- Improving health staff informatics competencies is important. Several options to accomplish this include: (1) including a basic module within medical school curricula, (2) developing an informatics certificate that can be conducted through e-learning and requiring it for all health staff, and (3) developing supporting policies for skill development (eg, specifying institutions to manage e-learning at the provincial and regional levels and identifying cadres that will supervise and oversee implementation of e-learning efforts).

- Infrastructure needs for innovation should be anticipated. This includes: (1) hardware and software associated with biometrics to reduce duplication, (2) smartphones for collection and transmission of data entry through voice recognition software, and (3) decentralised servers to expedite data movement and increase granular data access across the country.

these systems further to improve health and adopt new WHO norms (box 1). Although we have developed the functional capacity to generate most key data required to guide the HIV/AIDS response, there remain issues related to data completeness and quality. During the next phase, we hope that data use will become more common at both national and subnational levels and motivate the health workforce to collect, analyse, interpret and use health data. This change to a data-driven culture may lead staff to invest into improving its quality. We hope our experience will help other countries develop, strengthen and link health information systems.

Contributors VHS, AA-Q and ABS conceived the study. VHS and ABS drafted the manuscript. $A A-Q$ revised the manuscript for important intellectual content. VHS, $A A-Q$ and $A B S$ have read and meet the ICMJE criteria for authorship and agree with the results and conclusions of the manuscript.

Disclaimer The opinions and statements in this article are those of the authors and do not necessarily represent the official policy, endorsement or views of their organisations.

Competing interests None declared.

Patient consent Not required.

Provenance and peer review Not commissioned; externally peer reviewed.

Data sharing statement This Practice article contains no data other than that presented from published reports found in the references section.

Open access This is an open access article distributed in accordance with the Creative Commons Attribution Non Commercial (CC BY-NC 4.0) license, which 
permits others to distribute, remix, adapt, build upon this work non-commercially, and license their derivative works on different terms, provided the original work is properly cited, appropriate credit is given, any changes made indicated, and the use is non-commercial. See: http://creativecommons.org/licenses/by-nc/4.0/.

\section{REFERENCES}

1. United Nations General Assembly Resolution 70/1, 2015. Transforming our world: the 2030 Agenda for Sustainable Development. http://www.un.org/ga/search/view_doc.asp?symbol= A/RES/70/1\&Lang=E (accessed 4 Nov 2015).

2. United Nations General Assembly, 2016. Political Declaration on HIV and AIDS: On the Fast Track to Accelerating the Fight against HIV and to Ending the AIDS Epidemic by 2030. ResolutionA/RES/70/266 http://www.un.org/en/ga/search/view_doc.asp?symbol=A/RES/70/ 266 (accessed 24 Oct 2016).

3. Granich R, Gupta S, Hall I, et al. Status and methodology of publicly available national HIV care continua and 90-90-90 targets: A systematic review. PLoS Med 2017;14:e1002253.

4. World Health Organization, 2017. Consolidated guidelines on person-centred HIV patient monioring and case-based surveillance. http://apps.who.int/iris/bitstream/10665/255702/1/9789241512633eng.pdf

5. World Health Organization, 2007. WHO case definitions of HIV for surveillance and revised clinical staging and immunological classification of HIV-related disease in adults and children. http:// www.who.int/hiv/pub/guidelines/HIVstaging150307.pdf (accessed 31 May 2017).

6. Viet Nam Ministry of Health. Developing and strengthening the HIV testing system in Vietnam. Memories from the last 60 years of preventive medicine in Vietnam. 2016.

7. Viet Nam Ministry of Health. Circular 1418: Regulations on HIV/AIDS control in Viet Nam. 2000.

8. Viet Nam Ministry of Health. Circular 09: Guidance on HIV/AIDS and STI surveillance. 2012.

9. Viet Nam Authority on HIV/AIDS Control. Results of national HIV case reporting, AIDS case reporting, and death reporting review. 2015.

10. Viet Nam Authority on HIV/AIDS Control. 2016 National HIV/AIDS Report. 2016.
11. World Health Organization, 2003. Treating 3 million by 2005 : the WHO strategy to make it happen. http://www.who.int/3by5/ publications/documents/en/3by5StrategyMakingltHappen.pdf

12. Viet Nam Ministry of Health. Circular 03: Guidance on routine reporting of HIV/AIDS indicators. 2015.

13. Viet Nam National Assembly. Law on HIV/AIDS prevention and control. 2006.

14. Viet Nam Ministry of Health. Decision 28: Monitoring and evaluation for HIV/AIDS. 2008.

15. Ho Chi Minh City Provincial AIDS Center. Utilization \& functionality of eClinica: results from a rapid assessment of the HCMC HIV/AIDS program electronic health records system. 2014.

16. Viet Nam National Assembly. Health insurance law. 2008.

17. Viet Nam National Assembly. Decree 158: Civil status registration and management. 2005 (accessed 28 Aug 2017).

18. Rao C, Osterberger B, Anh TD, et al. Compiling mortality statistics from civil registration systems in Viet Nam: the long road ahead. Bull World Health Organ 2010;88:58-65.

19. Viet Nam Ministry of Health. Circular 27: Requirements for health statistics in provincial, district, and commune health facilities. 2014.

20. Joint United Nations Programme on HIV and AIDS, 2014. Considerations and guidance for countries adopting national health identifiers. http://www.unaids.org/sites/default/files/media asset/ JC2640_nationalhealthidentifiers_en.pdf (accessed 12 June2017).

21. Viet Nam Ministry of Justice. Decree 05: The people's identity card. 1999.

22. Vietnamnet bridge, 2015. Vietnam plans to issue new identification cards from January. http://english.vietnamnet.vn/fms/society/ 149454/vietnam-plans-to-issue-new-identification-cards-fromjanuary.html.

23. Viet Nam Social Security. Decision 1314: Issuance of an identifier in medical insurance cards. 2014

24. Viet Nam National Assembly. Decree 176: Provisions on sanctioning of administrative violations in the health domain. 2013.

25. The World Bank, 2017. GNI per capita, Atlas method (current US\$). http://data. worldbank.org/indicator/NY.GNP.PCAP.CD?locations=VN (accessed 8 Jun 2017).

26. Viet Nam Authority on HIV/AIDS Control. Case-Based Surveillance \& Monitoring Analysis in Vietnam: Opportunities for Improvement. 2016.

27. Viet Nam Authority on HIV/AIDS Control. Report on verification of HIV cases in Nghe An province. 2014. 